\title{
Determinants of the use of modern contraceptive methods among adolescents and young girls at the University of Yaounde I
}

\author{
Essiben Felix $^{1,2 *}$, Meka Esther ${ }^{1,2}$, Sap Suzanne ${ }^{1,2}$, Ayissi Gregory ${ }^{1,2}$, Embolo Manga Josépine Gertrude ${ }^{3}$ and Mbu Enow Robinson ${ }^{1,2}$ \\ ${ }^{1}$ Faculty of Medicine and Biomedical Sciences, The University of Yaounde I, Yaounde, Cameroon \\ ${ }^{2}$ Department of Obstetrics and Gynecology Faculty of Medicine and Biomedical Sciences, The University of Yaounde I, Yaounde, Cameroon \\ ${ }^{3}$ Higher Institute of Medical Technology, University of Douala, Cameroon
}

\begin{abstract}
Background: In Cameroon, more than a third of maternal deaths occur among adolescent girls and young mothers. Unwanted pregnancies resulting from the infrequent use of modern contraceptive methods (MCMs) are one of the main causes of death in this population.

Objective: To identify the determinants of modern contraceptive use among adolescents and young girls at the University of Yaounde I (UYI).

Patient and method: We carried out a case-control study over a 7 months period, in female students aged between 15-24 years old at the UYI. We compared female student using MCMs with those who didn't use MCMs. We studied their socio-demographic characteristics, gyneco-obstetrical history and knowledge of MCMs. Data were analyzed with statistically significant threshold set at $\mathrm{p}$-value $\leq 0.05$.

Results: In this study, 702 women were included amongst which 234 cases and 438 controls. The findings indicated that: women over the age of 19 (aOR = 2.18), with partner as a source of income $(\mathrm{aOR}=1,96)$, those who had coitarche before the age of $15(\mathrm{aOR}=4.25)$, women with a history of STIs $(\mathrm{aOR}=2.97)$, abortion $(\mathrm{aOR}=4.33)$ and pregnancy $(\mathrm{aOR}=2.07)$, or those with knowledge on MCMs $(\mathrm{aOR}=6.77)$ were more likely to use contraceptives than their counterparts.

Conclusion: Several socio-demographic, gynaeco-obstetrical and economic factors influence the use of MCMs by adolescent girls and young women in universities. Quality education and efficient counseling on the use of MCMs in pre-university settings could contribute towards reducing maternal mortality in our country.
\end{abstract}

\section{Introduction}

Maternal mortality is a major public health challenge in Cameroon with an estimated rate of 782 per 100000 live births. It remains a dilemma because young mothers and adolescent girls contribute to more than a third of cases [1]. According to the National Statistics Institute in 2015, young girls aged b15 to 24 years constituted $10.4 \%$ of the Cameroon population and less than $15 \%$ of these were using a modern contraceptive method [2] leading to unintended pregnancies which greatly contributed to high maternal and neonatal mortality through increased risk for unsafe abortion, birth injuries and postpartum depression.

Modern contraception refers to technological advances designed to overcome biology. This includes methods like pills, condoms, intrauterine devices, injectables etc. which prevent pregnancy by interfering with the normal processes of ovulation, fertilization and implantation [3] Contraceptive use is persistently low among young girls [4]. In a systematic review in Sub-Saharan Africa, Blackstone et al found that negative factors prohibiting contraceptive use were women's misconceptions of contraceptive side-effects, male partner disapproval, and social/cultural norms surrounding fertility. On the other hand, positive factors included education, employment, and communication with male partner [5].

In Cameroon, Essiben et al found that factors preventing the use of modern contraceptive methods among sexually active adolescent girls included living with both parents, not living with one's mother, unable to talk about sexuality with one's peers, the practice of anal coitus as well as ignorance regarding injectable contraceptive methods [6]. Hence how about factors determining the use of modern contraceptive in adolescent girls and young women?

We sought to determine those factors in a case control study among adolescent girls and young women at the YIU to obtain evidence towards reducing maternal mortality in this population in our country.

\section{Patients and method}

\section{Method}

We carried out a case-control study over a 7 months period (from the 1st November 2018 to the 31 May 2019) at the University of Yaoundé I (UYI). Our study population consisted of adolescent girls and young

${ }^{*}$ Correspondence to: Essiben Félix, Faculty of Medicine and Biomedical Sciences, The University of Yaoundé I, Yaounde, Cameroon, E-mail: essibenx@yahoo.com

Key words: determinants, modern contraceptive methods, adolescent girls, young women, University, Yaoundé

Received: September 23, 2019; Accepted: October 16, 2019; Published: October 21,2019 
women aged between 15-24 years old. We compared each case (female student using modern contraceptive method) with two controls (female student who didn't use modern contraceptive method).

\section{Data}

socio-demographic characteristics (age, religion, region, marital status and source of income), gyneco-obstetrical history (age of first sexual intercourse, number of sexual partners, history of STIs, history of pregnancy, age of first pregnancy, number of children, history of abortion) and knowledge of modern contraceptive methods were collected through a pre-tested survey form in female students of the Faculty of Sciences of the UYI, aged between 15-24 years old through group interviews after obtaining their informed consent. An authorization was obtained beforehand from the Institutional Ethics committee for Research on Human Health of the University of Douala and administrative authorization of the faculty of Sciences of the University of Yaoundé I.

\section{Patients}

In this study, 702 women were included, with 234 cases and 438 controls; Inclusion criteria were female students aged between 15-24 years old, using modern contraceptive methods (cases), and female students aged between 15-24 years old who didn't use modern contraceptive method (controls). All the patients were in bachelor level at The Faculty of Sciences of the UYI. Students of others Faculties, less or above the age range of the study or those who didn't consent to participate and male students were not included. Those with incomplete survey forms were excluded. Included female students were recruited through a pre-tested survey form after obtaining their informed consent.

\section{Statistical analysis}

Descriptive statistics, bivariate and multivariate logistic regressions were performed to assess socio-demographic characteristics, gynecoobstetrical history and knowledge of modern contraceptive methods. Crude Odds Ratio (COR) and Adjusted Odds Ratio (AOR) with their corresponding 95\% confidence intervals (95\% CI) were computed using the Statistical Package for the Social Sciences version 22.0. The significance threshold was set at 0.05 .

\section{Results}

\section{Socio-demographic features}

The study population was mainly over 19 years of age $(54.40 \%)$. The mean age was $20 \pm 1.6$ years. Most of them were single (85.3\%). The students were mostly in bachelor level I (51.1\%) and the Christian religion was the most represented $(76.35 \%)$. Parents were the major source of income in this study (Table 1).

\section{Use of modern contraceptive method}

The most widely used modern contraceptive method was the male condom (42.3\%) followed by the Pill (37.6\%) (Figure 1). Personal desire for contraception was main reason for using modern contraceptive methods (58.6\%) (Table 2). Similarly, the most common reason given for students not using a modern contraceptive method was personal refusal (50.2\%) (Table 3).

\section{Knowledge of modern contraceptive method}

The most common source of information about MCMs in our population was school $(68.1 \%)$ followed by health care providers
Table 1. Socio-demographic features

\begin{tabular}{|l|c|c|}
\hline Variables & Number (n) & Frequency (\%) \\
\hline Age (years) & 320 & 45.6 \\
$\quad[15-19]$ & 382 & 54.4 \\
{$[19-24]$} & & \\
Education level (Bachelor) & 359 & 51.1 \\
I & 266 & 37.9 \\
II & 77 & 11 \\
III & & \\
& & \\
Religion & 536 & 76.35 \\
Christian & 120 & 17.1 \\
Muslim & 46 & 6.55 \\
Other & & \\
& 55 & 7.8 \\
Marital status & 599 & 85.3 \\
Married & 48 & 6.9 \\
Single & & \\
Cohabiting & & 74.5 \\
Source of income & 523 & 18.7 \\
Parents & 131 & 6.8 \\
Partner & 48 & \\
Other & & \\
\hline
\end{tabular}

Table 2. Distribution of the population according by motivating factor for contraceptive use

\begin{tabular}{|c|c|c|}
\hline Variable & n (234) & Frequency (\%) \\
\hline Personal desire & 137 & 58.6 \\
\hline Following childbirth & 22 & 9.4 \\
Following abortion & 31 & 13.2 \\
\hline Partner desire & 38 & 16.2 \\
\hline Other & 6 & 2.6 \\
\hline
\end{tabular}

Table 3. Distribution of the population according to reasons for not using modern contraceptive methods

\begin{tabular}{|l|c|c|}
\hline Variable & n & Frequency (\%) \\
\hline Partner refusal & 45 & 9.6 \\
\hline High financial cost & 15 & 3.2 \\
\hline Access difficulties to health facilities & 4 & 0.85 \\
\hline Prohibition by religion & 41 & 8.8 \\
\hline Prohibition by custom & 11 & 2.35 \\
\hline Personal refusal & 235 & 50.2 \\
\hline Others & 131 & 28 \\
\hline
\end{tabular}

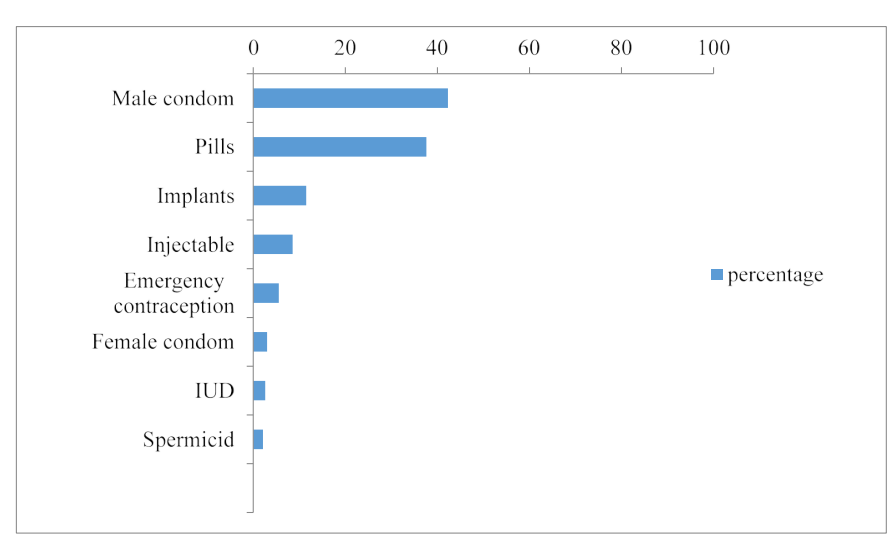

Figure 1. Distribution of the study population by contraceptive method used

(45.1\%) (Table 4). The male condom was the most known modern contraceptive method (100\%) followed by the pill $(72.5 \%)$ and the female condom (39.3\%) (Figure 2). 


\section{Summary of statistically significant predictors of modern contraceptive use after bivariate analysis}

In this study predictive factors determining modern contraceptive use among adolescent girls and young women after bivariate analysis were: the age $>19$ years $(\mathrm{OR}=2.33,95 \% \mathrm{CI}=1.72-3.18)$, being in bachelor level $2(\mathrm{OR}=1.38,95 \% \mathrm{CI}=1.03-1.85)$, marital status $(\mathrm{OR}$ $=1.89,95 \% \mathrm{CI}=1.14-3.12)$ or cohabiting with a partner $(\mathrm{OR}=1.94$, $95 \% \mathrm{CI}=1.14-3.30)$, the partner as a source of income $(\mathrm{OR}=3.48$, 95\% CI $=2.45-4.95$ ), the first sexual intercourse before 15 years old $(\mathrm{OR}=2.61,95 \% \mathrm{CI}=1.45-4.84)$, having only one sexual partner $(\mathrm{OR}$ $=2.54,95 \% \mathrm{CI}=1.89-3.42)$, history of sexual transmitted infections $(\mathrm{OR}=6.93,95 \% \mathrm{CI}=4.07-12.14)$, pregnancy $(\mathrm{OR}=4.07,95 \% \mathrm{CI}$ $=2.67-6.24)$ and abortion $(\mathrm{OR}=7.53,95 \% \mathrm{CI}=4.65-12.46)$; age of first pregnancy $>15(\mathrm{OR}=7.87,95 \% \mathrm{CI}=1.04-193.78)$, knowledge on modern contraceptive methods $(\mathrm{OR}=10.5,95 \% \mathrm{CI}=4.2-34.41)$, health providers $(\mathrm{OR}=2.07,95 \% \mathrm{CI}=1.54-2.80)$ and friends as source of information $(\mathrm{OR}=1.49,95 \% \mathrm{CI}=1.07-2.06)$ (Table 5).

\section{Summary of statistically significant predictors of modern contraceptive use after multivariate analysis}

In this study predictive factors determining modern contraceptive use among adolescent girls and young women after multivariate analysis were: the age $>19(\mathrm{AOR}=2.18 ; 95 \% \mathrm{CI}=1.46-3.27)$, the partner as a source of income $(\mathrm{AOR}=1,96 ; 95 \% \mathrm{CI}=1.08-3.59)$, the first sexual intercourse before age $15(\mathrm{AOR}=4.25 ; 95 \% \mathrm{CI}=2.13-8.52)$, history of STIs $(\mathrm{AOR}=2.97 ; 95 \% \mathrm{CI}=1.59-5.59)$, abortion $(\mathrm{AOR}=4.33 ; 95 \% \mathrm{CI}$ $=2.43-7.75)$ and pregnancy $(\mathrm{AOR}=2.07,95 \% \mathrm{CI}=1.22-3.59)$, as well as knowledge on modern contraceptive methods ( $\mathrm{AOR}=6.77,95 \% \mathrm{CI}$ $=2.33-19.69$ ) Table 6 .

\section{Discussion}

Family planning is one of the globally recognized essential strategies for reducing maternal mortality [7] and acting on adolescent girls and young women would yield to more conclusive results.

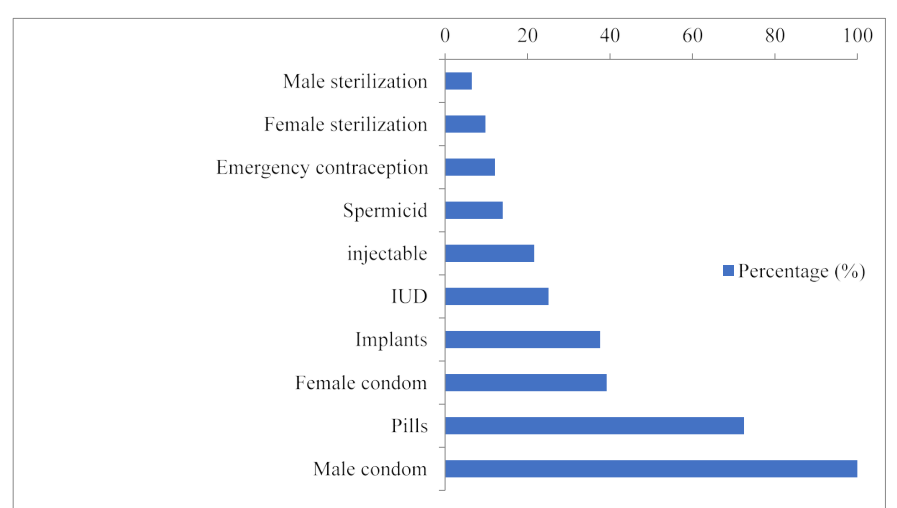

Figure 2. Student's distribution according to the Knowledge on modern contraceptive method

Table 4. Distribution of the population according to the source of information on MCM

\begin{tabular}{|c|c|c|}
\hline Variables & n & Frequency (\%) \\
\hline School & 429 & 68.1 \\
\hline Health care providers & 284 & 45.1 \\
\hline Media & 262 & 41.6 \\
\hline Family & 158 & 25.1 \\
\hline Friends & 170 & 27 \\
\hline Internet & 18 & 2.9 \\
\hline
\end{tabular}

Table 5. Summary of statistically significant predictors of modern contraceptive use after bivariate analysis

\begin{tabular}{|l|c|c|c|c|}
\hline Variables & Cases n (\%) & Controls n (\%) & OR (CI) & P-value \\
\hline Age >19 years & $158(41.3)$ & $224(58.7)$ & $2.33(1.72-3.18)$ & 0.000 \\
\hline Bachelor level II & $102(38.3)$ & $167(61.7)$ & $1.38(1.03-1.85)$ & 0.034 \\
\hline Married & $26(47.3)$ & $29(52.7)$ & $1.89(1.14-3.12)$ & 0.011 \\
\hline Cohabiting & $23(47.9)$ & $25(52.1)$ & $1.94(1.14-3.30)$ & 0.011 \\
\hline $\begin{array}{l}\text { Partner as source of } \\
\text { income }\end{array}$ & $76(58.0)$ & $55(42.0)$ & $3.48(2.45-4.95)$ & 0.000 \\
\hline $\begin{array}{l}\text { First sexual } \\
\text { intercourse }<15\end{array}$ & $37(47.4)$ & $41(52.6)$ & $2.61(1.45-4.84)$ & 0.001 \\
\hline Unique partner & $118(46.8)$ & $134(53.2)$ & $2.54(1.89-3.42)$ & 0.000 \\
\hline History of STIs & $42(75)$ & $14(25)$ & $6.93(4.07-12.14)$ & 0.000 \\
\hline Pregnancy number $\geq 1$ & $53(63.1)$ & $31(36.9)$ & $4.07(2.67-6.24)$ & 0.000 \\
\hline $\begin{array}{l}\text { First pregnancy after } \\
15 \text { years }\end{array}$ & $49(62)$ & $30(38)$ & $7.87(1.04-193.78)$ & 0.040 \\
\hline History of abortion & $55(77.5)$ & $16(22.5)$ & $7.53(4.65-12.46)$ & 0.000 \\
\hline Knowledge on MCM & $234(37.1)$ & $396(62.9)$ & $10.5(4.2-34.41)$ & 0.000 \\
\hline $\begin{array}{l}\text { Health provider as } \\
\text { source of information }\end{array}$ & $122(43.0)$ & $162(57.0)$ & $2.07(1.54-2.80)$ & 0.000 \\
\hline $\begin{array}{l}\text { Friend as source of } \\
\text { information }\end{array}$ & $69(40.6)$ & $101(59.4)$ & $1.49(1.07-2.06)$ & 0.016 \\
\hline
\end{tabular}

Table 6. Summary of statistically significant predictors of modern contraceptive use after multivariate analysis

\begin{tabular}{|l|c|c|c|}
\hline \multicolumn{1}{|c|}{ Variables } & aOR & $\mathbf{9 5 \%}$ CI & P-value \\
\hline Age $>19$ & 2.19 & $1.46-327$ & 0.0001 \\
\hline Married & 0.43 & $0.19-0.93$ & 0.0334 \\
\hline Partner as source of income & 1,97 & $1.08-3.59$ & 0.0280 \\
\hline First sexual intercourse $<15$ & 4.26 & $2.13-8.52$ & $<0.0001$ \\
\hline History of STIs & 2.97 & $1.59-5.59$ & 0.0007 \\
\hline Pregnancy number $\geq 1$ & 2.07 & $1.22-3.59$ & 0.0069 \\
\hline History of abortion & 4.34 & $2.43-7.75$ & $<0.0001$ \\
\hline Knowledge on MCMs & 6.77 & $2.33-19.69$ & 0.0004 \\
\hline
\end{tabular}

We observed that the study population was mainly over 19 years and women above this age were two-fold likely to use MCMs than adolescents aged 15-19 years. Indeed, in the Demographic Health Survey (DHS) 2011 in Cameroon, there was an increase of $5 \%$ in MCMs use between adolescent aged 15-19 years than their counterpart aged 20-24 years. Several barriers such as concerns about confidentiality and parental notification, cost, knowledge deficits among adolescents and health care providers... could explain the low contraceptive use in the age bracket of 15-19 years versus 20-24 years [4]. On the other hand, women aged 20-24 years understand the consequences of engaging in unprotected sexual act or without contraceptive use compared to adolescents. Our results concur with the findings of previous studies in Malawi and Nepal which also reported reduced contraceptive use among adolescents compared to women aged 20-24 years [2,8].

Being married was a factor preventing MCMs use among women in our study, contrasting with results of Afriyie et al in Ghana [9]. This difference can be due to the fact that, their study included women aged 18-49 years and married women in our study were young and seeking for children. We further observed that female students who had partner as source of income were approximately two-fold likely to use MCMs than those who had parents as income source. Indeed, students who depend on the partner as a source of income may have a higher rate of sexual exposure than those who depend on parents, and because of their educational status in this study, they may manifest greater awareness on the dangers of unprotected sexual intercourse and unintended pregnancies [10]. 
The students who had started sexual activity before the age of 15 where 4-fold more likely to use MCMs while those who had an history of STIs where thrice as likely to use MCMs. Indeed, students with early sexual activity would have more experience than those who start their sexual lives later and would be more confronted with early and unintended pregnancies, abortions and STIs leading to an increase in contraceptives use among them. Different results were found by Tamang et al who found that the non-use of MCMs was associated with young age at first sexual intercourse, and this was linked to the influence of religion on MCMs use as he included Hindus in his study [11]. In a study conducted to identify factors associated with a history of sexually transmitted infections in Ghanaian women 15 - 24 years Ohene et al. found that compared to those denying a history of STI, the STIs group was more likely to use a condom at their last sexual encounter $(27 \%$ vs $17 \%, p=0.003)$. Thus going in line with our finding, suggesting that women with STIs history have greater awareness as per the consequences of STIs and are more likely to prevent it in further relationships [12].

Our findings indicated that women with history of pregnancy and abortion were respectively two and four-fold more at risk to use MCMs than their counterparts. Similar results were found by Geremew et al. who showed that MCMs use was associated with pregnancy history but also indicated that the risk of MCMs use decreased with parity. He concluded that, providing modern contraceptives targeting grand multiparous women is crucial [13]. Women who had an abortion may experience pain, stress, and endanger their lives when it is done under unsafe conditions especially in a country where it remains prohibited as it is in Cameroon [14]. Therefore, they would be more likely to use MCMs than the others. In a study involving 1,176 women aged 15-49 years which aimed to examine associations between abortion history and use of a modern contraceptive method among women in Luanda, Morris et al found that a history of induced abortion was associated with use of a MCMs and the commonest contraceptive used by those women was condoms [15], as is it in our study, indicating that despite adoption of a MCM, many women are still at risk for an unintended pregnancy. Indeed the effectiveness of male condoms for pregnancy prevention depends upon whether they are used consistently and correctly. With consistent, correct use, the pregnancy rate is $2 \%$; with typical use it is $18 \%$ [ 4$]$.

Knowledge on MCMs was the most important determinant of their use in this study. Indeed knowledge on MCMs is significantly associated with the educational level as is it in many published studies $[2,5,8,9,13]$, and our study population consisted of young girls in undergraduate studies at university. Therefore, the link between knowledge and use of MCMs appears logically and clearly in our study. Education empowers women to have autonomy in making important decisions regarding fertility related issues and also helps them exercise reproductive health rights compared to uneducated women. Moreover, educated women could probably have a better understanding of the benefits of using contraception to reduce unintended pregnancies than women with no education. For that reason, it is necessary that family planning service providers must place special emphasis on, and address the needs of women with little or no health knowledge education during family planning sessions to provide them with basic reproductive knowledge to improve uptake of contraceptives [2]. Moreover, it may be important for policy makers in Cameroon to formulate and enforce policies that promote quality education and efficient counseling on the use of modern contraceptive methods in pre-university settings to reduce maternal mortality in our country.
Some limits of this study should be considered. Sexuality is still a taboo subject in our environment. Discussion group preceding the distribution of the questionnaires could have influence the students' responses.

\section{Conclusion}

In this study, the determinants of modern contraceptive methods use were the age $>19$, being married, the partner as source of income, the first sexual intercourse before the age of 15, the history of STIs, pregnancy number $\geq 1$, and abortion and Knowledge on MCMs. The determinants identified are factors that educators can rely on to increase the protection of these young, vulnerable students. Pregnancy among female students occurs under difficult socio-economic conditions and contributes to thwarting their academic and life projects. Female students will resort to clandestine abortions because Cameroonian law is restrictive in this respect and secure abortions are not accessible. Education before admission to university will give them attitudes and behaviors that allow them to adopt contraceptive methods.

\section{Contribution of authors}

Essiben Félix designed the study and analyzed results. Essiben Félix and Ayissi Gregory wrote the article, Manga Gertrude collected the data, Meka Esther, Sap Suzanne reviewed and provided critical comments and suggestions for the manuscript.

\section{Competing interests}

All the authors do not have any possible conflicts of interest and declare that they have no competing interests; this work was not sponsored by any organization and was self-financed.

\section{Acknowledgements}

We thank the Dean of the Faculty of Sciences and his staff as well as the students reoresentatives who facilitated student recruitment.

\section{References}

1. Donatus L, Sama DJ, Tsoka-Gwegweni JM, Cumber SN (2018) Factors associated with adolescent school girl's pregnancy in Kumbo East Health District North West region Cameroon. Pan Afr Med J 31: 138. [Crossref]

2. Mandiwa C, Namondwe B, Makwinja A, Zamawe C (2018) Factors associated with contraceptive use among young women in Malawi: analysis of the 2015-16 Malawi demographic and health survey data. Contracept Reprod Med 3: 12. [Crossref]

3. Hubacher D, Trussell J (2015) A definition of modern contraceptive methods Contraception 92: 420-421. [Crossref]

4. Chacko R Mariam. Contraception: Issues specific to adolescents - UpToDate [Internet] [cited 2019 Aug 21]

5. Blackstone SR, Nwaozuru U, Iwelunmor J (2017) Factors Influencing Contraceptive Use in Sub-Saharan Africa: A Systematic Review. Int Q Community Health Educ 37: 79-91. [Crossref]

6. Essiben F, Ngo Um Meka E, Foumane P, Epoupa Mpacko CD, Ojong S, et al. (2018) Factors preventing the use of modern contraceptive methods in sexually active adolescents in Yaounde. Obstet Gynecol Reports.

7. Ganatra B, Faundes A (2016) Role of birth spacing, family planning services, safe abortion services and post-abortion care in reducing maternal mortality. Best Pract Res Clin Obstet Gynaecol 36: 145-155. [Crossref]

8. Subedi R, Jahan I, Baatsen P (2018) Factors influencing modern contraceptive use among adolescents in Nepal. J Nepal Health Res Counc 16: 251-256.

9. Afriyie P, Tarkang EE (2019) Factors influencing use of modern contraception among married women in Ho West district, Ghana: descriptive cross-sectional study. Pan Afr Med J 33:15. [Crossref] 
Essiben F (2019) Determinants of the use of modern contraceptive methods among adolescents and young girls at the University of Yaounde I

10. Tekelab T, Melka AS, Wirtu D (2015) Predictors of modern contraceptive methods use among married women of reproductive age groups in Western Ethiopia: a community based cross-sectional study. BMC Womens Health 15: 52. [Crossref]

11. Tamang L, Raynes-Greenow C, McGeechan K, Black K (2017) Factors associated with contraceptive use among sexually active Nepalese youths in the Kathmandu Valley. Contracept Reprod Med 2: 13. [Crossref]

12. Ohene S, Akoto I (2008) Factors associated with sexually transmitted infections among young Ghanaian women. Ghana Med J 42: 96. [Crossref]
13. Geremew AB, Gelagay AA (2018) Modern contraceptive use and associated factors among married women in Finote Selam town Northwest Ethiopia: a community based cross-sectional study. Women's Midlife Heal 4: 13. [Crossref]

14. Say L, Chou D, Gemmill A, Tunçalp Ö, Moller A-B, et al. (2014) Global causes of maternal death: a WHO systematic analysis. Lancet Glob Heal.

15. Morris N, Prata N (2018) Abortion history and its association with current use of modern contraceptive methods in Luanda, Angola. Open Access J Contracept. 9: 4555.

Copyright: (C2019 Essiben F. This is an open-access article distributed under the terms of the Creative Commons Attribution License, which permits unrestricted use, distribution, and reproduction in any medium, provided the original author and source are credited. 